\title{
The role of impulsivity in the aetiology of drug dependence: reward sensitivity versus automaticity
}

\author{
Lee Hogarth
}

Received: 1 July 2010 /Accepted: 7 January 2011 /Published online: 8 February 2011

(C) The Author(s) 2011. This article is published with open access at Springerlink.com

\begin{abstract}
Rationale Impulsivity has long been known as a risk factor for drug dependence, but the mechanisms underpinning this association are unclear. Impulsivity may confer hypersensitivity to drug reinforcement which establishes higher rates of instrumental drug-seeking and drug-taking behaviour, or may confer a propensity for automatic (non-intentional) control over drug-seeking/taking and thus intransigence to clinical intervention.

Method The current study sought to distinguish these two accounts by measuring Barratt Impulsivity and craving to smoke in 100 smokers prior to their completion of an instrumental concurrent choice task for tobacco (to measure the rate of drug-seeking) and an ad libitum smoking test (to measure the rate of drug-taking - number of puffs consumed).

Results The results showed that impulsivity was not associated with higher rates of drug-seeking/taking, but individual differences in smoking uptake and craving were. Rather, nonplanning impulsivity moderated (decreased) the relationship between craving and drug-taking, but not drug-seeking.

Conclusions These data suggest that whereas the uptake of drug use is mediated by hypervaluation of the drug as an instrumental goal, the orthogonal trait nonplanning impulsivity confers a propensity for automatic control over well-practiced drug-taking behaviour.
\end{abstract}

Keywords Addiction · Habit · Compulsion · Goal-directed · Nicotine

L. Hogarth $(\bowtie)$

School of Psychology, University of Nottingham,

University Park,

Nottingham NG7 2RD, UK

e-mail: Lee.Hogarth@nottingham.ac.uk

\section{Introduction}

Impulsivity has long been thought to play a role in the aetiology of drug dependence, but the mechanisms underpinning this association remain to be clarified. Prevailing evidence indicates that impulsivity and drug use are co-morbid (Stanford et al. 2009) and that impulsivity both pre-dates (Ersche et al. 2010; Tarter et al. 2004; VerdejoGarcía et al. 2008) and is exacerbated by drug exposure (Dallery and Locey 2005; Heil et al. 2006; Setlow et al. 2009; Winstanley 2007) suggesting their relationship is reciprocal (De Wit 2009; Everitt et al. 2008; Perry and Carrol 2008). The question, therefore, is how impulsivity influences drug-seeking/taking to enhance dependence.

One possibility is that impulsivity confers hypersensitivity to drug reinforcement which establishes higher rates of drug-seeking/taking. This claim is supported by the finding that impulsivity in rats, quantified by preference for small immediate reward over a delayed larger reward (delay discounting) is associated with higher rates of cocaine (Anker et al. 2009; Perry et al. 2005; Perry et al. 2008), alcohol (Poulos et al. 1995) and methylphenidate selfadministration (Marusich and Bardo 2009). Similarly, impulsivity in rats, assessed by premature responding in the five-choice serial reaction time task (five-choice), is associated with reduced $\mathrm{D} 2$ receptor availability and higher rates of cocaine self-administration (Dalley et al. 2007; see also Le Foll et al. 2009). In turn, reduced D2 availability is associated with higher rates of cocaine self-administration in monkeys (Nader et al. 2006) and more positive subjective liking of methylphenidate in humans (Volkow et al. 1999; Volkow et al. 2002). Finally, human impulsivity indexed by the Barratt Impulsivity Scale (BIS; Stanford et al. 2009) is associated with reduced dopamine D2 receptor availability in the striatum (Lee et al. 2009), 
implying that BIS impulsivity should be linked to higher rates of self-administration.

The alternative possibility is that impulsivity does not influence drug reinforcement, but rather, facilitates automatic or habitual control of drug-seeking/taking behaviour by drug-associated stimuli. Evidence for this proposal comes from the finding that five-choice impulsive rats do not maintain higher rates of cocaine self-administration at baseline, but rather, show selective perseveration of selfadministration punished by electric shock (Belin et al. 2008; Economidou et al. 2009). Arguably, such perseverative self-administration is not mediated by the response-outcome contingency, but rather, is mediated by a crystallized, or compulsive, stimulus-response (S-R) association which renders the behaviour resistant to challenge (Belin et al. 2009; Everitt et al. 2008).

Further complexity in this area has been raised by Diergaarde et al. (2008). In this study, five-choice impulsive rats showed higher rate of nicotine self-administration (consistent with Dalley et al. 2007) but no perseveration of extinguished self-administration (inconsistent with Belin et al. 2008; Economidou et al. 2009), whereas delay discounting impulsive rats showed the converse pattern: equal rates of self-administration (inconsistent with Anker et al. 2009; Marusich and Bardo 2009; Perry et al. 2005; Perry et al. 2008; Poulos et al. 1995) and perseveration of extinguished self-administration (consistent with Belin et al. 2008; Economidou et al. 2009). It may be concluded from these mixed data that vulnerability to dependence is conferred by two dissociable traits, sensitivity to drug reinforcement and impulsive-automaticity, but the optimal methods for discriminating these two traits and assessing their unique impact on behaviour remains to be determined.

Human self-administration studies have produced similar mixed results. Although a number of human selfadministration paradigms have been developed (Bisaga et al. 2007; Fischman and Foltin 1992; Haney 2009; Hart et al. 2001; Harvey et al. 2004; Lamb et al. 1991; Leeman et al. 2010; McKee et al. 2009; Panlilio et al. 2005; Ray et al. 2006; Silverman et al. 1994; Spiga et al. 2005), only three studies appear to have examined the relationship with impulsivity (Dallery and Raiff 2007; Mueller et al. 2009; Walsh et al. 2010). In two studies (Dallery and Raiff 2007; Mueller et al. 2009), smokers could earn money in accordance with the time for which they refrained from puffing on a cigarette or initiating smoking, and delay discounting impulsivity predicted higher rates of puffing and a shorter latency to initiate smoking, respectively. However, it is not clear whether impulsivity conferred hypersensitivity to tobacco reward or hyposensitivity to punishment in the form of money loss. By contrast, Walsh et al. (2010) found that cocaine-dependent participants had a greater hedonic response to cocaine and higher rates of cocaine self-administration compared to cocaine abusers, yet the two groups were equated for BIS impulsivity, suggesting impulsivity was orthogonal to the reinforcement value of cocaine. The current study was undertaken to address these unresolved questions concerning the relationship between impulsivity and drug self-administration.

In the current experiment, a sample 100 relatively young adult smokers were recruited, containing an equal proportion of daily and non-daily smokers to ensure a broad variation in smoking uptake (cigarettes per week). Craving was measured with the questionnaire of smoking urges (Cox et al. 2001), and impulsivity was assessed with the BIS (Patton et al. 1995). Then, the rate of drug-seeking was assessed using a concurrent choice procedure (for reviews see Ahmed 2010; Hursh and Silberberg 2008). In each trial, participants could press one key to earn cigarette points or a second key to earn chocolate points, and each key had a $50 \%$ probability of yielding its respective reward in any given trial. Previous studies employing human instrumental learning tasks in which an arbitrary response yields tobacco puffs (Bühler et al. 2010; Perkins et al. 1994; Willner et al. 1995), cocaine pictures (Moeller et al. 2009) or cocaine (Walsh et al. 2010) have shown that response rate/ percent is predicted by drug use severity and craving. Thus, smoking uptake and craving were expected to predict increased percent tobacco over chocolate responding in the concurrent choice task. The question at stake was whether BIS impulsivity would also be associated with increased percent choice of tobacco, suggesting hypersensitivity to drug reinforcement, or would be uncorrelated with this measure of drug-seeking, suggesting that impulsivity plays a dissociable role in the aetiology of dependence.

Drug-taking was then assessed in an ad libitum smoking session, where the number of puffs consumed was the critical measure. Previous studies using ad libitum smoking have shown that the number of puffs consumed is associated with smoking uptake and craving (Bisaga et al. 2007; Leeman et al. 2010; see also Brauer et al. 1996), and so uptake and craving were expected to predict increased puff number in the current study. The question at stake was whether BIS impulsivity would also be associated with increased drug-taking, suggesting greater sensitivity to drug reinforcement, or would be uncorrelated with drug-taking, suggesting a dissociable role in dependence.

The second objective was to determine the link between impulsivity and automatic control of drug-seeking/taking. Numerous methodologies have been claimed to isolate automatic or implicit process in addiction, but most fall short of the strict criteria required for this conclusion (Debner and Jacoby 1994; Lieberman et al. 1998; Lovibond and Shanks 2002; Seth et al. 2008; Shanks and St. John 1994). According to one criterion, behaviour is demonstrably automatic if its performance is dissociated from the subjec- 
tively reported intention of the individual (Jacoby 1991). In applying this criterion to addiction, Tiffany (1990) proposed that drug-seeking/taking may be identified as automatic if this behaviour is uncorrelated with subjective craving. A similar point was made by Robinson and Berridge (1993) in their wanting-liking dissociation. On this rationale, the current study quantified the automaticity of drug-seeking/ taking by its decoupling (null correlation) from subjective craving to smoke, using moderation analysis. The question at stake was whether BIS impulsivity would moderate the correlation between craving and drug-seeking/taking, suggesting a propensity to automatic control over these behaviours as proposed by Tiffany (1990).

Learning theory anticipates that drug-seeking and drug-taking should acquire different levels of automaticity. The basis for this suggestion comes from the animal devaluation procedure. In this procedure, rats are first trained on a drug or reward-seeking response before the incentive value of the outcome is devalued by satiety/taste aversion or revalued by abstinence. In the test that follows, rats have the opportunity to perform the drug/reward-seeking response in extinction to determine if they can use an expectation of the outcome to control their behaviour. Responding that is sensitive to the devaluation/revaluation treatment in the extinction test is identified as goal-directed insomuch as this behaviour must be mediated by rats' knowledge of the response-outcome (R-O) contingencies established in training combined with knowledge of the current incentive value of the outcome acquired during the devaluation/ revaluation treatment (Dickinson and Balleine 2010). By contrast, drug/reward-seeking is demonstrably automatic (or habitual) if its performance is insensitive to the devaluation/revaluation treatment. In this case, the behaviour is arguably elicited directly by the instrumental context as a S-R habit, without the animal retrieving knowledge of the outcome of that behaviour, i.e. the behaviour is decoupled from intention.

The development of habitual control over natural rewarded behaviour is favoured by overtraining or practice (Dickinson et al. 1995; Killcross and Coutureau 2003; Tricomi et al. 2009), by the availability of a single response option (Kosaki and Dickinson 2010) and by responses that are proximal to the ingestion of the reinforcer (Balleine et al. 1995; Corbit and Balleine 2003). Moreover, these factors appear to be important for the development of habitual drug-seeking (Dickinson et al. 2002; Glasner et al. 2005; Miles et al. 2003; Zapata et al. 2010) versus goaldirected drug-seeking (Hutcheson et al. 2001; Olmstead et al. 2001). The implication for the current study is that because the concurrent choice test of drug-seeking incorporates factors that favour goal-directed control (minimal training, multiple response options, distance from ingestion), whereas the ad libitum smoking test of drug-taking incorporates factors that favour habitual control (overtraining, single response option, proximity to ingestion), one would expect greater automatic control over drugtaking. Accordingly, it is anticipated that impulsivity could selectively moderate the correlation between craving and drug-taking, but not drug-seeking, suggesting that the propensity for automatic control is limited to behaviours that have received training conditions favourable to the development of automaticity.

\section{Method and materials}

\section{Participants}

One hundred smokers were recruited for the study. Half reported daily and half reported non-daily smoking to ensure broad variance in uptake. Ten participants consumed an outlying number of puffs $( \pm 3 \mathrm{SD})$ in the ad libitum consumption test, that is, three participants consumed three or fewer puffs and seven participants consumed 27 or greater puffs. These participants were excluded to avoid undue influence of outliers and to allow puff number to be transformed to a normal distribution, which are essential for the stability of regression analysis (Draper and John 1981). The remaining 90 participants had a average age of 21.4 $(3.4,18-40)$, smoked $4.8(2.5, .2-7)$ days per week, in which days they smoked $5.8(4.0,1-20)$ cigarettes, smoked for $4.5(3.5, .5-27)$ years, starting at an age of 16.9 (2.6, 11-31) and reported a smoking urges score of $3.4(1.5,1-$ 6.8) for factor 1 and $1.5(0.7,1-4.3)$ for factor 2 (brackets contain SD followed by the range min-max). There were 47 males and 43 females and 44 daily and 46 non-daily smokers in the analysed sample.

\section{Apparatus and materials}

Questionnaires established age, gender, smoking days per week, cigarettes smoked on smoking days, time since last cigarette, smoking years, age of smoking onset and questionnaire of smoking urges (QSU-Cox et al. 2001) using a revised scoring protocol (Cappelleri et al. 2007), which yielded factor 1, reflecting a desire to smoke for the rewarding consequences, and factor 2 , reflecting anticipation of relief from negative withdrawal. The BIS version 11 was used to measure impulsivity (Stanford et al. 2009). This questionnaire contains three subscales: (1) Motor impulsivity, e.g. "I do things without thinking", which assesses propensity for action without thought, (2) nonplanning impulsivity, e.g. "I plan tasks carefully", which assesses capacity for purposive future action and (3) attentional impulsivity, e.g. "I don't pay attention", which assesses capacity for sustained attention. The concurrent choice task 
was generated with E-prime software (Psychology Software Tools, Inc. pstnet.com) on a standard PC.

\section{Concurrent choice task (drug-seeking)}

Immediately following these questionnaires, participants completed a concurrent choice task to quantify rate of drugseeking. Participants were first presented with the on-screen instructions: "This is a game in which you imagine winning cigarettes and chocolate. In each round, either $1 / 4$ of a cigarette or $1 / 4$ of a chocolate bar will be available, but you will not be told which. Choose either the D or H key in each round to try and win the reward. You will only win if you select the correct key. Good luck. Press the space bar to begin".

Each trial began with the central text, "Select a key" presented for between 1 and $5 \mathrm{~s}$. Pressing either the $\mathrm{D}$ or $\mathrm{H}$ key in this period yielded the outcome text "You win 1/4 of a cigarette", which overwrote the "Select a key" text at its termination, whereas pressing the other key yielded the outcome text "You win 1/4 of a chocolate bar". These outcomes were presented for $2 \mathrm{~s}$ followed by and random inter-trial interval of 1,000 to $2,500 \mathrm{msec}$. The $\mathrm{D}$ and $\mathrm{H}$ key were counterbalanced between participants in their production of the tobacco and chocolate outcome, and each key had only a $50 \%$ chance of yielding its outcome in any given trial. On non-rewarded trials, the text "You win nothing" was presented. Participants had no way of predicting which key would be reinforced in any given trial.

There were five blocks of 12 trials, and each block comprised two cycles of three tobacco and three chocolate outcomes scheduled randomly across six trials, such that no more than three of the same outcome could occur in succession within a block. Earned outcomes were summed across trials, and at the end of each 12-trial block, a "totalizer" screen reported the quantity of each reward type earned. Where whole cigarettes or chocolate bars had been earned, participants were instructed to move that many units from two boxes present on the table, which contained 15 Marlboro Lights cigarettes and 15 Cadbury Dairy Milk treat size chocolate bars (15 g), respectively, into "their box" present alongside. In this way, participants contacted the earned rewards, although they were aware that they would not keep them at the end of the experiment. The critical measure was the percentage of trials in which the tobacco key was selected.

\section{Ad libitum smoking session (drug-taking)}

Immediately following the concurrent choice task, participants were told that they were free to take a break in which they could smoke. They were sent outside the building for a fixed 10-min interval to smoke as much or as little as they wished and they recorded on a sheet of paper each puff consumed to measure drug-taking. Given the importance of overtraining in encouraging habitual behaviour, and the possibility that any alteration in the behavioural sequence would reengage intentional control (Daw et al. 2005), the objective of this ad libitum test was to be natural and avoid experimental intervention as far as possible, apart from the tick sheet on which each puff was recorded. Participants were paid $£ 5$ for participation, and the Nottingham School of Psychology Ethics committee approved the study.

\section{Results}

Data were normally distributed or transformed to a normal distribution prior to analysis ( $p$ values $>0.05$ ). The index of smoking uptake was cigarettes smoked per week (smoking days per week $\times$ cigarettes smoked on smoking days). Relationships were first tested with Pearson correlations, followed by regression to isolate the contribution of the various predictors. Data were centred prior to moderation analysis. All figures reported the actual data (untransformed/ uncentred) for ease of interpretation. A threshold of $p<.05$ defined significance in all analyses. Smoking urges factor 2 was omitted from the analysis as it showed no significant associations.

\section{Predicting drug-seeking/taking}

Figure 1a-d shows that drug-seeking and taking were predicted by cigarettes per week (uptake) and smoking urges factor 1 (craving) but not by BIS impulsivity scales (Fig. 1e-j). Table 1 shows the hierarchical regression undertaken to contrast these two sets of predictors. Drug-seeking or taking were entered as the dependent variable with the BIS scales as predictors at level 1, and these associations were again non-significant. By contrast, when cigarette per week or smoking urges factor 1 were added as predictors at level 2, the proportion of variance accounted for increased significantly. Thus, drug-seeking/taking were significantly more strongly predicted by uptake and craving than by BIS impulsivity, suggesting that BIS impulsivity does not increase sensitivity to drug reinforcement.

Multiple regression was undertaken to test whether the relationships between drug-seeking/taking and uptake/craving could be accounted for other individual differences. Again, drug-seeking or taking were entered as the dependent variable with uptake or craving as the predictors, along with age, time since a cigarette, smoking years and age of smoking onset. In each of these four regressions, only the uptake and craving measures served as significant independent predictors, 

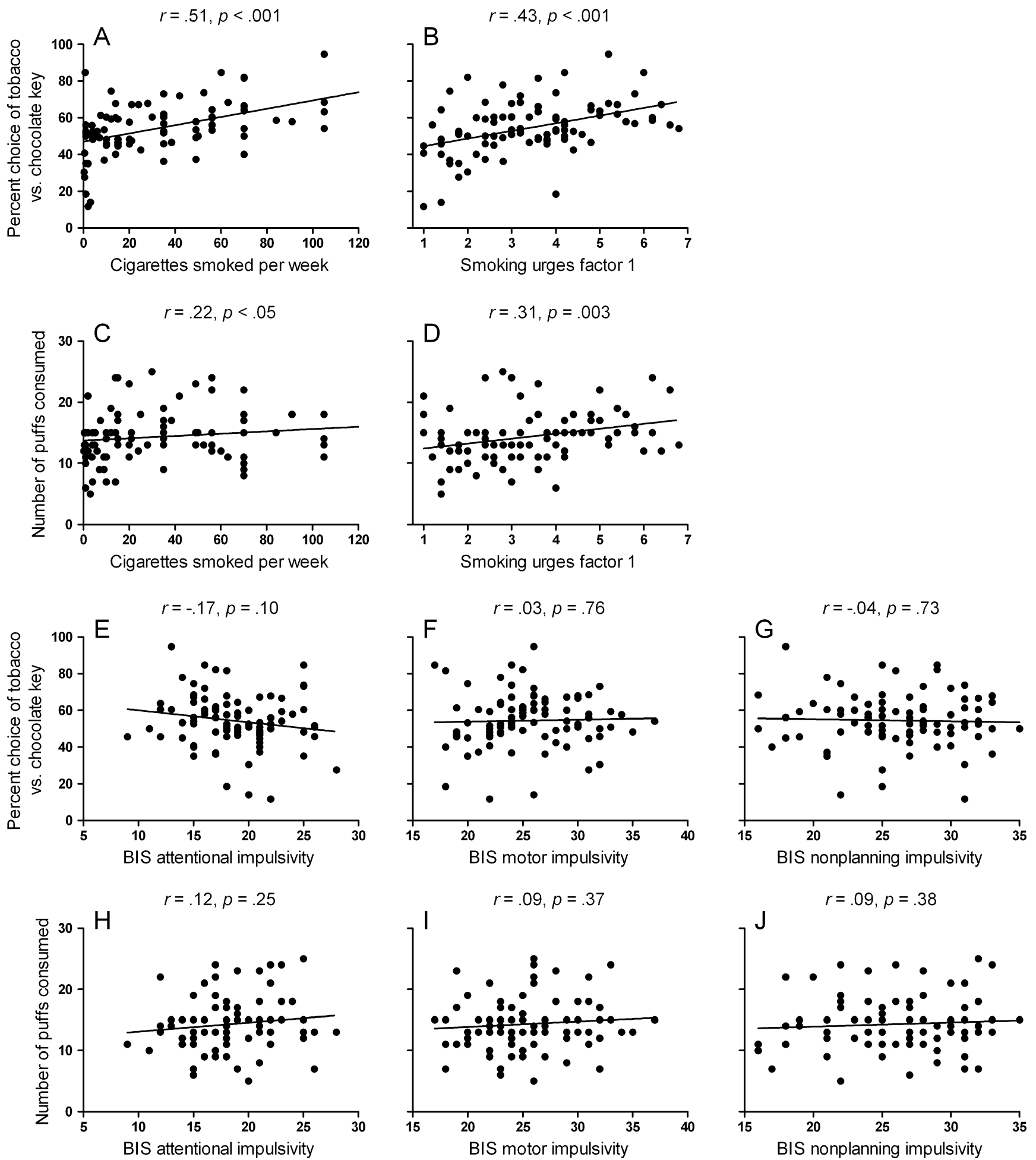

Fig. 1 a-d Scatterplots showing the extent to which cigarettes per week (uptake) and smoking urges factor 1 (craving) predict percent tobacco responses in the concurrent choice task (drug-seeking) and

number of puffs consumed in the ad libitum smoking session (drugtaking). $\mathbf{e}-\mathbf{j}$ Scatterplots showing the extent to which Barratt Impulsivity Scales (BIS) predict the drug-seeking and drug-taking measures

$t$ values $>2.15, p$ values $\leq .03$, whereas the other variables were all unreliable, $t$ values $<-1.43, p$ values $>.15$. These analyses indicate that the association between uptake/craving and drug-seeking/taking cannot be attributed to age, chro- nicity or recency of smoking. Finally, uptake/craving measures were not reliably correlated with the BIS impulsivity scales, $r$ values $<.19, p$ values $>.08$, suggesting these traits are orthogonal. 
Table 1 Hierarchical regression with percent tobacco choice (drug-seeking) or number of puffs consumed (drug-taking) as the dependent variables

\begin{tabular}{llllllrr}
\hline Dependent variable & Level & Level 2 predictor & $R$ & $R^{2}$ & $R^{2}$ change & $F$ change & $p$ \\
\hline Percent tobacco choice & 1 & 3 BIS scales & .20 & .04 & .04 & 1.28 \\
& 2 & Uptake & .52 & .27 & .23 & 26.46 \\
Number of puffs consumed & 1 & Craving & .46 & .21 & .17 & $.000^{*}$ \\
& 2 & 3 BIS scales & .14 & .02 & .02 & $.000^{*}$ \\
& & Uptake & .27 & .07 & .05 & .55 \\
\hline
\end{tabular}

The three BIS impulsivity scales were predictors in level 1 (ns.). The level 2 predictors were either cigarettes per week (uptake) or smoking urges factor 1 (craving), and these predictors increased the proportion of variance accounted for significantly over the BIS scales. $d f$ - level $1=3,86$ and level $2=1,85$

\section{Moderation analysis}

Moderation analysis was conducted to determine if impulsivity influenced the strength of relationship between smoking urges factor 1 and drug-seeking/taking. For this purpose, hierarchical regression was conducted in which either percent tobacco choice (seeking) or number of puffs consumed (taking) were entered as dependent variables. In the first level, centred values for the independent variable, smoking urges factor 1 , were entered, along with centred values for the moderator variables (the three impulsivity scales in separate tests), creating six tests in total. In the second level of these tests, the centred values for the product of the independent and moderator variables were entered, and this interaction term was tested for significance in the change of the $R^{2}$. Table 2 shows the interaction term for each of these six tests. These analyses showed that BIS nonplanning impulsivity moderated the relationship between smoking urges factor 1 and drug-taking behaviour, as shown in Fig. 2a, that is, craving and drugtaking became decoupled with nonplanning impulsivity. By contrast, there were no other significant moderation effects. Figure $2 b$ shows the non-significant moderation effect with drug-seeking, to highlight the selectivity of this effect to drug-taking.
Simple slope analysis (Jose 2008) on Fig. 2a indicated that the relationship between smoking urges factor 1 and drug-taking was significant for the low BIS nonplanning group, $t=4.13, p<.001$, and the median BIS nonplanning group, $t=2.88, p=.005$, but not for the high BIS nonplanning group, $t=.13, p=.90$. These analyses indicate that drug-taking became progressively decoupled from subjective craving as BIS nonplanning impulsivity increased. Moreover, nonplanning impulsivity was not reliably correlated with age, smoking years, age of smoking onset or time since a cigarette, $r$ values $<.13, p$ values $>.22$, indicating that the development of automatic drug-taking could not be attributed to age, chronicity or recency of smoking. Finally, Levene's test indicated that the three nonplanning groups (low, median, high) showed no difference in the variance or either puff number of smoking urges factor $1, F$ values $<1$, indicating that the loss of correlation between puff number and smoking urges factor 1 could not be attributed to differential constraint on the variance of these measures imposed by ceiling or floor effects.

\section{Discussion}

In this study, a sample of smokers who varied in their uptake of smoking reported their craving to smoke and

Table 2 Moderation analyses examining the impact of BIS impulsivity on the association between smoking urges factor 1 and drug-seeking/ taking (see text for details)

\begin{tabular}{llllrr}
\hline Dependent variable & Moderator variable & $R$ & $R^{2}$ & $R^{2}$ change & $F$ change \\
\hline Percent tobacco choice & BIS attention & .48 & .23 & .03 & 3.45 \\
& BIS motor & .43 & .19 & .00 & .07 \\
Number of puffs consumed & BIS nonplanning & .43 & .18 & .00 & .52 \\
& BIS attention & .34 & .12 & .00 & .02 \\
& BIS motor & .33 & .11 & .00 & .04 \\
& BIS nonplanning & .42 & .17 & .07 & .80 \\
\hline
\end{tabular}

BIS nonplanning impulsivity moderated the relationship between smoking urges factor 1 and drug-taking (number of puffs consumed), but all other moderation effects were unreliable $(d f=1,86)$ 


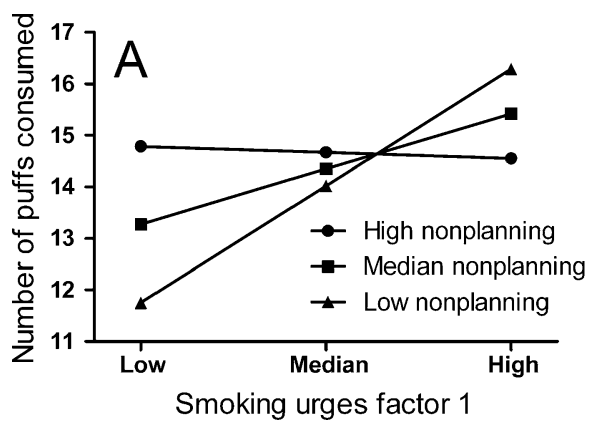

Fig. 2 a Simple slopes analysis showing the change in association between smoking urges factor 1 (craving) and number of puffs consumed in the ad libitum smoking session (drug-taking) as a function of three levels of BIS nonplanning impulsivity (low, median, high). The progressive reduction in the association between craving

impulsivity before tobacco-seeking and taking behaviour were measured experimentally. The result showed that impulsivity was not associated with higher rates of drugseeking/taking, contrary to the view that impulsivity confers hypersensitivity to drug reinforcement. In contrast, uptake and craving were associated with higher rates of drug-seeking and taking, which could not be accounted for by age, recency or chronicity of smoking, and this uptake/ craving trait was orthogonal (uncorrelated) with impulsivity. These findings suggest that drug uptake is mediated by hypersensitivity to drug reinforcement, which establishes greater intentional drug-seeking/taking reflected in subjective craving, whereas impulsivity plays a dissociable role in the aetiology of dependence. The finding that nonplanning impulsivity moderated the association between craving and drug-taking suggests, in accordance with Tiffany's (1990) criteria, that nonplanning impulsivity confers a propensity for automatic (non-intentional) control over drug-taking. At the same time, the null moderation effect with drug-seeking suggests that the propensity to automatic control in nonplanning impulsivity extends only to behaviours that have undergone training that favours automatic control. The overall conclusion, therefore, is that two orthogonal vulnerabilities, hypersensitivity to drug reinforcement and propensity to automatic control, play dissociable roles in the aetiology of dependence.

This dual-process account of dependence vulnerability reconciles two paradoxical literatures. One set of literature suggests that dependence is mediated by sensitivity to drug reinforcement, which establishes greater intentional drug choice, indexed by the hedonic response to drugs (Scherrer et al. 2009; Volkow et al. 2009; Walsh et al. 2010), craving (Allen et al. 2008; Killen and Fortmann 1997), positive expectancies (Campbell and Oei 2010; Herd et al. 2009; Leventhal and Schmitz 2006), instrumental response rate (Dalley et al. 2007; Le Foll et al. 2009; Moeller et al. 2009; Nader et al. 2006; Walsh et al. 2010) and economic demand

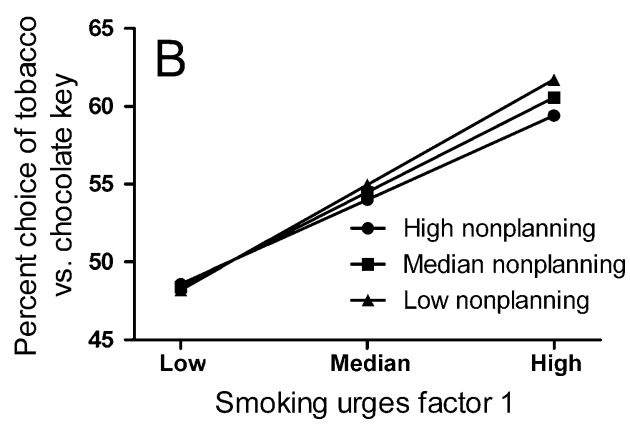

and drug-taking across levels of nonplanning impulsivity is indicative of a transition to automatic (non-intentional) control of drug-taking. b Simples slopes analysis with percent tobacco choice (drug-seeking) as the dependent measure, shows no comparable decoupling from craving across levels of nonplanning impulsivity

(Bickel et al. 2000; MacKillop et al. 2010). By contrast, the other set of literature suggests that dependence is mediated by automaticity, or the loss of intentional control over behaviour, indexed by effects of drugs on impulsive responding (Dallery and Locey 2005; Heil et al. 2006; Setlow et al. 2009; Winstanley 2007), habit formation (Dickinson et al. 2002; Jedynak et al. 2007; Nelson and Killcross 2006), fronto-executive impairment (Dom et al. 2005; Garavan and Hester 2007; Goldstein et al. 2009; London et al. 2000) and perseveration of selfadministration under punishment (Belin et al. 2008; Deroche-Gamonet et al. 2004; Economidou et al. 2009; Pelloux et al. 2007; Vanderschuren and Everitt 2004) and extinction (Diergaarde et al. 2008). It is believed that these two dissociable traits, hypersensitivity to drug reinforcement and propensity to automatic control, have independent genetic substrates (Breitling et al. 2009; Dalley and Everitt 2009; Furberg et al. 2010; Sherva et al. 2008) and play a differential role in the uptake and clinical perseveration of drug use, respectively (Belin et al. 2009; Everitt et al. 2008; Goldstein et al. 2009).

The current data are at odds with studies which have shown impulsive rats to acquire higher rates of selfadministration (Anker et al. 2009; Dalley et al. 2007; Marusich and Bardo 2009; Perry et al. 2005; Perry et al. 2008; Poulos et al. 1995). One explanation for this discrepancy is suggested by the finding that the effect of impulsivity on the rate of self-administration in animals is dependent upon the dose, length of training and reinforcement rate (see in particular Marusich and Bardo 2009). Thus, it is possible that the current drug-seeking/taking schedules were not optimized to detect an effect of impulsivity. However, because the ad libitum smoking test approximated "normal" human self-administration, the absence of an impulsivity effect here rather calls into question the generality of this effect in animal selfadministration. 
The second source of variance between these studies is the tests of impulsivity employed. Whereas the current study used the BIS, the animal designs used delay discounting or five-choice, and these assays are likely to tap only partially overlapping arrays of traits (de Wit et al. 2007). Two human studies which have indexed impulsivity with delay discounting have shown an association with higher rates of smoking in the laboratory (Dallery and Raiff 2007; Mueller et al. 2009). However, as noted, smoking in these studies was offset against money loss, so higher rates could have been driven by hyposensitivity to punishment, i.e. automaticity, rather than sensitivity to nicotine reinforcement (Belin et al. 2008; Economidou et al. 2009). On the other hand, Walsh et al. (2010) found that although dependence status predicted rate of cocaine self-administration, BIS impulsivity did not, corroborating the current finding. Thus, although there is converging evidence that BIS impulsivity does not mark sensitivity to drug reinforcement, it remains possible that other assays of impulsivity do so; although in humans, this remains to be established in the absence of punishment.

Higher rates of drug-seeking in individuals with greater uptake arguably highlight the importance of goal-directed learning in dependence vulnerability. On this goal-directed account, when deciding which key to press in the concurrent choice task, participants retrieved a representation of the two outcomes, "You win 1/4 of a cigarette" and "You win 1/4 of a chocolate bar", and the incentive value ascribed to each outcome provided evaluative feedback to determine the propensity to select the associated response (R-O; de Wit and Dickinson 2009). Arguably, this retrieval of incentive value added a bias to the selection of the higher valued outcome (Baum 1974), above and beyond the ongoing tabulation of local reinforcement rates which ensured a high degree of switching and general tendency towards equal distribution between the two responses (Herrnstein 1961; Staddon 1992). The claim that retrieval of the incentive value of tobacco determined preferential responding for this outcome, rather than this outcome simply establishing a stronger motoric propensity through the law of effect (Thorndike 1911) or S-R/reinforcement learning (Hull 1943), comes from the finding that this preference was associated with subjective craving. Strictly speaking, this correlational evidence does not support causal inferences. However, Cartesian accounts, which view craving as an epiphenomenon, are less parsimonious because they cannot explain why conscious experience should arise if not to play a causal role in action selection. More direct evidence, however, comes from the finding that selection of the two responses can be devalued in an extinction test (Hogarth and Chase 2011) indicating that choice is influenced by retrieval of a representation of the current incentive value of the outcome. Overall, therefore, these data converge on the view that the uptake of drug use is mediated by the hypervaluation of the drug as the outcome of goal-directed drug-seeking.

Goal-directed learning may also play a role in drugtaking, at least in low nonplanning impulsive participants. On this view, when low nonplanning impulsive participants raised the cigarette to their lips in the ad libitum test, this response was governed by a representation of the reward value of the inhalation, indexed by craving. By contrast, the decoupling of craving and drug-taking in high nonplanning impulsive participants suggests a transition to automatic control in these individuals. On this view, when high nonplanning impulsive individuals lifted the cigarette to their lips to inhale, this response was not governed by an expectation of the rewarding consequences, reflected in craving, but rather, was elicited directly by Pavlovian stimuli embedded within the smoking sequence (Ostlund et al. 2009), for example, by the sight of the cigarette, the time since the previous puff, the pneumatic parameters of the previous puff or interoceptive signals of taste, nicotine or blood oxygen (Nemeth-Coslett and Griffiths 1984a,b; Rose 2006).

There are three forms of automatic learning that could govern smoking behaviour in high nonplanning impulsive participants. By classic S-R/reinforcement learning (Hull 1943), nicotine reinforcement strengthens the association between stimuli (S) embedded within the smoking sequence and the puffing response (R), enabling in those $\mathrm{S}$ to elicit the R directly. By this S-R account, the high nonplanning impulsive smoker is a true automaton because no cognitive or motivational process mediates stimulus control of drug-taking. By contrast, two-process learning theory (Rescorla and Solomon 1967) suggests that cues embedded within the smoking sequence acquire through Pavlovian conditioning the capacity to elicit an excitatory motivational state $\left(\mathrm{O}^{\mathrm{m}}\right)$, such as physiological arousal (Carter and Tiffany 1999), akin to that elicited by the inhalation itself, which modulates S-R associations to evoke the puff response. On this view, a momentary arousal state mediates the cue effect on drug-taking $\left(\mathrm{S}-\mathrm{O}^{\mathrm{m}}-\mathrm{R}\right)$, but the taking response is nevertheless autonomous because the response is not governed by an explicit representation of the outcome.

According to S-O $\mathrm{O}^{\mathrm{S}}$ - $\mathrm{R}$ theory (Balleine and O'Doherty 2010; de Wit and Dickinson 2009; Ostlund and Balleine 2008), stimuli (S) embedded in the smoking sequence elicit a representation of the sensory features of the associated inhalation outcome $\left(\mathrm{O}^{\mathrm{S}}\right)$, which in turn elicits the puffing response $(\mathrm{R})$ through a bidirectional instrumental $\left(\mathrm{O}^{\mathrm{s}}-\mathrm{R}\right)$ association. On this view, high nonplanning impulsive smokers were cognitive agents because an expectation of the inhalation outcome mediated the puff response. However, this expectation incorporated only the sensory features of inhaling, which elicited the puff response 
automatically in the sense the representation of current value of that outcome $\left(\mathrm{O}^{v}\right)$ was not retrieved. The essential difference between these three accounts lies in the quality of the $\mathrm{O}$ representation retrieved to govern the puff response. The outcome representation is either entirely absent (S-R), restricted to a general motivational state $\left(\mathrm{S}-\mathrm{O}^{\mathrm{m}}-\mathrm{R}\right)$, or restricted to a sensory percept $\left(\mathrm{S}-\mathrm{O}^{\mathrm{s}}-\mathrm{R}\right)$. All three proposals converge on the view that automatic action ceases to be controlled by a representation of current incentive value of the outcome $\left(\mathrm{O}^{\mathrm{v}}\right)$.

Support an $\mathrm{S}-\mathrm{O}^{\mathrm{S}}-\mathrm{R}$ account of automatic drug use comes from three studies. Hogarth et al. (2010) paired a stimulus $(\mathrm{S}+)$ with the receipt of the tobacco outcome "You win $1 / 4$ of a cigarette", and then tested the ability of this stimulus to transfer control over puffing behaviour in an ad libitum smoking session. The results showed that across the smoking session, puff probability and craving declined, reflecting a decrease in the incentive value of smoking with satiety. By contrast, the capacity of the $\mathrm{S}+$ to enhance puff probability and craving remained unchanged, suggesting that the cue controlled puffing automatically, without making contact with the current incentive value of smoking (for corroboratory evidence, see Drobes and Tiffany 1997; Maude-Griffin and Tiffany 1996; Tiffany et al. 2000; Tiffany et al. 2007; Waters et al. 2004). Importantly, because the $\mathrm{S}+$ was not associated with the puffing response in training, this transfer of control could not be mediated by the formation of a direct S-R association (Colwill and Rescorla 1988) and must have involved retrieval of a representation of the outcome, either $\mathrm{O}^{\mathrm{m}}$ or $\mathrm{O}^{\mathrm{s}}$.

To discriminate these two possibilities, Hogarth et al. (2007) conducted an outcome-specific Pavlovian to instrumental transfer procedure (for a review see Holmes et al. 2010). In this design, initial discrimination training established two stimuli as predictors of tobacco or money reward, before instrumental training established two responses to earn these same outcomes. In the transfer test, each stimulus selectively augmented performance of the response that was associated with the same outcome, demonstrating that the transfer of control was mediated by each stimulus retrieving a representation of its associated outcome, which in turn elicited its associated response, i.e. transfer of control was mediated by S-O-R learning. Finally, in the third study of this series (Hogarth and Chase 2011, Experiment 2), this transfer effect was shown to be insensitive to devaluation, corroborating animal studies (Colwill and Rescorla 1990; Corbit et al. 2007; Holland 2004; Rescorla 1994). Thus, the outcome representation retrieved by the $\mathrm{S}$, which controlled action selection, was demonstrably restricted to the sensory percept of the outcome $\left(\mathrm{O}^{\mathrm{s}}\right)$ and did not make contact with the current incentive value of the outcome $\left(\mathrm{O}^{\mathrm{v}}\right)$. The implication is that high nonplanning impulsivity conferred a predisposition to this form of automatic $\mathrm{S}-\mathrm{O}^{\mathrm{S}}-\mathrm{R}$ based control of puffing behaviour, decoupling this behaviour from outcome value $\left(\mathrm{O}_{\mathrm{v}}\right)$ indexed by craving. The predominance of this automatic form of learning is potentially responsible for the intransigence of drug use to intentional regulation.

It is important to note that automaticity was restricted to drug-taking, whereas drug-seeking remained coupled to craving irrespective of impulsivity. This finding accords with animal studies which have found that insensitivity to devaluation (habit formation) is favoured by overtraining, restricted response options and the proximity of the response to ingestion (Corbit and Balleine 2003; Dickinson et al. 1995; Kosaki and Dickinson 2010). Thus, the selective decoupling of drug-taking from craving across nonplanning impulsivity may have arisen because the ad libitum consumption test contained procedural variables that favoured automatic control, i.e. the smoking sequence was overtrained, singular and proximal to ingestion. By contrast, the concurrent choice test may have remained coupled to craving irrespective of impulsivity because the responses measured in this test had received training favourable to goal-directed control, i.e. minimal training of multiple response options that were distal from ingestion. The implication is that automatic and goal-directed learning operate concurrently, but differentially influence behaviours depending upon their conditions of training (Balleine and O’Doherty 2010; Dickinson and Balleine 2010; Killcross and Coutureau 2003). The dominance of habit learning, however, may extend to behaviours that have undergone unfavourable training given sufficient neurotoxic insult (Jedynak et al. 2007; Killcross and Coutureau 2003; Nelson and Killcross 2006; Zapata et al. 2010), which could drive wide ranging automaticity in more clinically severe populations.

Several observations support the notion that automaticity plays a more prominent role in the longitudinal clinical preservation of drug use. First, the DSM-IV (1994) criteria for diagnosis of dependence favour constructs related to automaticity, such as perseveration despite costs and binging or chain consumption, rather than constructs to do with drug valuation, such as craving and expectancy. Indeed, we have recently found that BIS impulsivity was most strongly associated with these two automatic constructs of the DSM (Chase and Hogarth 2011). Second, the impact of public health information on cessation is dependent upon individual differences in the depth of cognitive processing of this information (Hammond et al. 2003) and education level of the individual (Heyman 2003), suggesting impaired cognition is important for clinical perseveration. Third, impulsivity has been associated with markers for clinical perseveration rather than uptake (Flory and Manuck 2009) and shows greater co-morbidity with substance misuse in adult versus adolescent populations (Biederman et al. 1997), is more strongly associated with 
treatment retention than with drug use severity (Moeller et al. 2001) see also (Schmitz et al. 2009) and has been associated with poorer quit rates after controlling for craving, dependence, age and affect (Doran et al. 2004). Although these findings are suggestive, the predominance of automatic learning in clinical perseveration remains to be tested using paradigms that fully support this conclusion.

It is difficult to explain why the BIS nonplanning scale alone was associated with automatic drug-taking. Across the BIS literature as a whole, the three scales (nonplanning, motor, attentional) show a somewhat chaotic pattern of associations with different diagnoses and psychometric assessments. However, several observations highlight nonplanning impulsivity as decisive predictor, beyond the other scales, which help build a notion of the mechanisms underpinning impulsive-automaticity. Specifically, nonplanning impulsivity has been associated with reduced volume of the right middle orbitofrontal cortex (OFC; Matsuo et al. 2009), reduced OFC volume and addiction in schizophrenics (Schiffer et al. 2010; which may exacerbate reduced medial OFC volume in smokers Kühn et al. 2010), delayed discounting (de Wit et al. 2007), a unique genetic substrate (Benko et al. 2010) and greater susceptibility to impairment of cued reaction time following tryptophan (5HT) depletion (Cools et al. 2005). Perhaps most curiously, Ersche et al. (2010) examined the impulsivity of siblings of drug users to determine whether impulsivity pre-exists drug exposure and found that siblings differed from controls only with respect to nonplanning impulsivity. By contrast, drug users differed from controls by all three scales, suggesting that the motor and attentional components are exacerbated by drug exposure. One can only speculate about how automatic consummatory behaviour accompanying nonplanning impulsivity may have conferred vulnerability to initiate drug use. One possibility is that automatic consummatory patterns more readily generalise from natural reward (food, sweets) to alcohol, tobacco and illicit drugs because the individual does not exert intentional control to stop this generalisation, easing the gateway into drug use, but this remains a speculation.

To conclude, the study found that impulsivity was not associated with increased frequency of drug-seeking and drug-taking behaviour, but individual differences in uptake and craving were. Rather, nonplanning impulsivity was associated with a decoupling of drug-taking from craving, suggesting this behaviour was automatic. However, this automaticity did not extend to drug-seeking, suggesting that nonplanning impulsivity only augments automatic control of behaviours which have undergone training favourable to automaticity. Overall, the study supports a dual-process account of dependence vulnerability wherein uptake is mediated by hypervaluation of the drug as an instrumental goal, whereas clinical perseveration is mediated by the formation of automatic or habitual drug consumption. It will be important for future research to assess whether the balance between these two learning processes changes as a function of drug class and chronicity of drug use.

Acknowledgements This manuscript was supported by an MRC Grant to Lee Hogarth (no. G0701456) at the University of Nottingham School of Psychology. The author would like to thank Nadja Heym for the helpful comments on an earlier draft.

Open Access This article is distributed under the terms of the Creative Commons Attribution Noncommercial License which permits any noncommercial use, distribution, and reproduction in any medium, provided the original author(s) and source are credited.

\section{References}

Ahmed SH (2010) Validation crisis in animal models of drug addiction: beyond non-disordered drug use toward drug addiction. Neurosci Biobehav Rev 35:172-184

Allen SS, Bade T, Hatsukami D, Center B (2008) Craving, withdrawal, and smoking urges on days immediately prior to smoking relapse. Nicotine Tob Res 10:35-45

Anker JJ, Perry JL, Gliddon LA, Carroll ME (2009) Impulsivity predicts the escalation of cocaine self-administration in rats. Pharmacol Biochem Behav 93:343-348

Balleine BW, O'Doherty JP (2010) Human and rodent homologies in action control: corticostriatal determinants of goal-directed and habitual action. Neuropsychopharmacology 35:48-69

Balleine BW, Garner C, Gonzalez F, Dickinson A (1995) Motivational control of heterogeneous instrumental chains. J Exp Psychol Anim Behav Process 21:203-217

Baum WM (1974) Two types of deviation from matching law-bias and undermatching. J Exp Anal Behav 22:231-242

Belin D, Mar AC, Dalley JW, Robbins TW, Everitt BJ (2008) High impulsivity predicts the switch to compulsive cocaine-taking. Science 320:1352-1355

Belin D, Jonkman S, Dickinson A, Robbins TW, Everitt BJ (2009) Parallel and interactive learning processes within the basal ganglia: Relevance for the understanding of addiction. Behav Brain Res 199:89-102

Benko A, Lazary J, Molnar E, Gonda X, Tothfalusi L, Pap D, Mirnics Z, Kurimay T, Chase D, Juhasz G, Anderson IM, Deakin JFW, Bagdy G (2010) Significant association between the C(-1019)G functional polymorphism of the HTR1A gene and impulsivity. Am J Med Genet B Neuropsychiatr Genet 153B:592-599

Bickel WK, Marsch LA, Carroll ME (2000) Deconstructing relative reinforcing efficacy and situating the measures of pharmacological reinforcement with behavioral economics: a theoretical proposal. Psychopharmacology 153:44-56

Biederman J, Wilens T, Mick E, Faraone SV, Weber W, Curtis S, Thornell A, Pfister K, Jetton JG, Soriano J (1997) Is ADHD a risk factor for psychoactive substance use disorders? Findings from a four-year prospective follow-up study. J Am Acad Child Adolesc Psychiatry 36:21-29

Bisaga A, Padilla M, Garawi F, Sullivan MA, Haney M (2007) Effects of alternative reinforcer and craving on the choice to smoke cigarettes in the laboratory. Hum Psychopharmacol Clin Exp 22:41-47

Brauer LH, Hatsukami D, Hanson K, Shiffman S (1996) Smoking topography in tobacco chippers and dependent smokers. Addict Behav 21:233-238 
Breitling LP, Dahmen N, Mittelstrass K, Illig T, Rujescu D, Raum E, Winterer G, Brenner H (2009) Smoking cessation and variations in nicotinic acetylcholine receptor subunits alpha-5, alpha-3, and beta-4 genes. Biol Psychiatry 65:691-695

Bühler M, Vollstädt-Klein S, Kobiella A, Budde H, Reed LJ, Braus DF, Büchel C, Smolka MN (2010) Nicotine dependence is characterized by disordered reward processing in a network driving motivation. Biol Psychiatry 67:745-752

Campbell JM, Oei TP (2010) A cognitive model for the intergenerational transference of alcohol use behavior. Addict Behav 35:73-83

Cappelleri JC, Bushmakin AG, Baker CL, Merikle E, Olufade AO, Gilbert DG (2007) Multivariate framework of the brief questionnaire of smoking urges. Drug Alcohol Depend 90:234-242

Carter BL, Tiffany ST (1999) Meta-analysis of cue-reactivity in addiction research. Addiction 94:327-340

Chase HW, Hogarth L (2011) Impulsivity and symptoms of nicotine dependence in a young adult population (under review)

Colwill RM, Rescorla RA (1990) Effects of reinforcer devaluation on discriminative control of instrumental behavior. J Exp Psychol Anim Behav Process 16:40-47

Colwill RM, Rescorla RA (1988) Associations between the discriminative stimulus and the reinforcer in instrumental learning. J Exp Psychol Anim Behav Process 14:155-164

Cools R, Blackwell A, Clark L, Menzies L, Cox S, Robbins TW (2005) Tryptophan depletion disrupts the motivational guidance of goal-directed behavior as a function of trait impulsivity. Neuropsychopharmacology 30:1362-1373

Corbit LH, Balleine BW (2003) Instrumental and Pavlovian incentive processes have dissociable effects on components of a heterogeneous instrumental chain. J Exp Psychol Anim Behav Process 29:99-106

Corbit LH, Janak PH, Balleine BW (2007) General and outcomespecific forms of Pavlovian-instrumental transfer: the effect of shifts in motivational state and inactivation of the ventral tegmental area. Eur J Neurosci 26:3141-3149

Cox LS, Tiffany ST, Christen AG (2001) Evaluation of the brief questionnaire of smoking urges (QSU-brief) in the laboratory and clinical settings. Nicotine Tob Res 3:7-16

Dalley JW, Everitt BJ (2009) Dopamine receptors in the learning, memory and drug reward circuitry. Semin Cell Dev Biol 20:403410

Dallery J, Locey ML (2005) Effects of acute and chronic nicotine on impulsive choice in rats. Behav Pharmacol 16:15-23

Dallery J, Raiff BR (2007) Delay discounting predicts cigarette smoking in a laboratory model of abstinence reinforcement. Psychopharmacology 190:485-496

Dalley JW, Fryer TD, Brichard L, Robinson ESJ, Theobald DEH, Laane K, Pena Y, Murphy ER, Shah Y, Probst K, Abakumova I, Aigbirhio FI, Richards HK, Hong Y, Baron J-C, Everitt BJ, Robbins TW (2007) Nucleus accumbens D2/3 receptors predict trait impulsivity and cocaine reinforcement. Science 315:1267-1270

Daw ND, Niv Y, Dayan P (2005) Uncertainty-based competition between prefrontal and dorsolateral striatal systems for behavioral control. Nat Neurosci 8:1704-1711

De Wit H (2009) Impulsivity as a determinant and consequence of drug use: a review of underlying processes. Addict Biol 14:22-31

de Wit S, Dickinson A (2009) Associative theories of goal-directed behaviour: a case for animal-human translational models. Psychol Res 73:463-476

de Wit H, Flory JD, Acheson A, McCloskey M, Manuck SB (2007) IQ and nonplanning impulsivity are independently associated with delay discounting in middle-aged adults. Pers Individ Differ 42:111-121

Debner JA, Jacoby LL (1994) Unconscious perception: attention, awareness and control. J Exp Psychol Learn Mem Cogn 20:304-317
Deroche-Gamonet V, Belin D, Piazza PV (2004) Evidence for addiction-like behavior in the rat. Science 305:1014-1017

Dickinson A, Balleine B (2010) The cognitive/motivational interface. In: Kringelbach ML, Berridge KC (eds) Pleasures of the brain. The neural basis of taste, smell and other rewards. Oxford University Press, Oxford, pp 74-84

Dickinson A, Balleine B, Watt A, Gonzalez F, Boakes RA (1995) Motivational control after extended instrumental training. Anim Learn Behav 23:197-206

Dickinson A, Wood N, Smith JW (2002) Alcohol seeking by rats: action or habit? Q J Exp Psychol B Comp Physiol Psychol 55:331-348

Diergaarde L, Pattij T, Poortvliet I, Hogenboom F, de Vries W, Schoffelmeer ANM, De Vries TJ (2008) Impulsive choice and impulsive action predict vulnerability to distinct stages of nicotine seeking in rats. Biol Psychiatry 63:301-308

Dom G, Sabbe B, Hulstijn W, Van Den Brink W (2005) Substance use disorders and the orbitofrontal cortex-systematic review of behavioural decision-making and neuroimaging studies. $\mathrm{Br} \mathrm{J}$ Psychiatry 187:209-220

Doran N, Spring B, McChargue D, Pergadia M, Richmond M (2004) Impulsivity and smoking relapse. Nicotine Tob Res 6:641-647

Draper NR, John JA (1981) Influential observations and outliers in regression. Technometrics 23:21-26

Drobes DJ, Tiffany ST (1997) Induction of smoking urge through imaginal and in vivo procedures: physiological and self-report manifestations. J Abnorm Psychol 106:15-25

DSM-IV (1994) Diagnostic and statistical manual of mental disorders (4th edn). American Psychiatric Association, American Psychiatric Association

Economidou D, Pelloux Y, Robbins TW, Dalley JW, Everitt BJ (2009) High impulsivity predicts relapse to cocaine-seeking after punishment-induced abstinence. Biol Psychiatry 65:851-856

Ersche KD, Turton AJ, Pradhan S, Bullmore ET, Robbins TW (2010) Drug addiction endophenotypes: impulsive versus sensationseeking personality traits. Biological Psychiatry 68(8):770-773

BJ BD, Economidou D, Pelloux Y, Dalley JW, Robbins TW (2008) Neural mechanisms underlying the vulnerability to develop compulsive drug-seeking habits and addiction. Philosophical Transactions of the Royal Society B 363:3125-3135

Fischman MW, Foltin RW (1992) Self-administration of cocaine by humans - a laboratory perspective. Ciba Found Symp 166:165180

Flory JD, Manuck SB (2009) Impulsiveness and cigarette smoking. Psychosom Med 71:431-437

Furberg H, Kim Y, Dackor J, Boerwinkle E, Franceschini N, Ardissino D, Bernardinelli L, Mannucci PM, Mauri F, Merlini PA, Absher D, Assimes TL, Fortmann SP, Iribarren C, Knowles JW, Quertermous T, Ferrucci L, Tanaka T, Bis JC, Furberg CD, Haritunians T, McKnight B, Psaty BM, Taylor KD, Thacker EL, Almgren P, Groop L, Ladenvall C, Boehnke M, Jackson AU, Mohlke KL, Stringham HM, Tuomilehto J, Benjamin EJ, Hwang SJ, Levy D, Preis SR, Vasan RS, Duan J, Gejman PV, Levinson DF, Sanders AR, Shi JX, Lips EH, McKay JD, Agudo A, Barzan L, Bencko V, Benhamou S, Castellsague X, Canova C, Conway DI, Fabianova E, Foretova L, Janout V, Healy CM, Holcatova I, Kjaerheim K, Lagiou P, Lissowska J, Lowry R, Macfarlane TV, Mates D, Richiardi L, Rudnai P, Szeszenia-Dabrowska N, Zaridze D, Znaor A, Lathrop M, Brennan P, Bandinelli S, Frayling TM, Guralnik JM, Milaneschi Y, Perry JRB, Altshuler D, Elosua R, Kathiresan S, Lucas G, Melander O, O'Donnell CJ, Salomaa V, Schwartz SM, Voight BF, Penninx BW, Smit JH, Vogelzangs N, Boomsma DI, de Geus EJC, Vink JM, Willemsen G, Chanock SJ, Gu FY, Hankinson SE, Hunter DJ, Hofman A, Tiemeier H, Uitterlinden AG, van Duijn CM, Walter S, Chasman DI, Everett BM, Pare G, Ridker PM, Li MD, Maes HH, Audrain- 
McGovern J, Posthuma D, Thornton LM, Lerman C, Kaprio J, Rose JE, Ioannidis JPA, Kraft P, Lin DY, Sullivan PF (2010) Genome-wide meta-analyses identify multiple loci associated with smoking behavior. Nat Genet 42:441-U134

Garavan H, Hester R (2007) The role of cognitive control in cocaine dependence. Neuropsychol Rev 17:337-345

Glasner SV, Overmier JB, Balleine BW (2005) The role of Pavlovian cues in alcohol seeking in dependent and nondependent rats. J Stud Alcohol 66:53-61

Goldstein RZ, Craig AD, Bechara A, Garavan H, Childress AR, Paulus MP, Volkow ND (2009) The neurocircuitry of impaired insight in drug addiction. Trends Cogn Sci 13:372-380

Hammond D, Fong GT, McDonald PW, Cameron R, Brown KS (2003) Impact of the graphic Canadian warning labels on adult smoking behaviour. Tob Control 12:391-395

Haney M (2009) Self-administration of cocaine, cannabis and heroin in the human laboratory: benefits and pitfalls. Addict Biol 14:9-21

Hart CL, Ward AS, Haney M, Foltin RW, Fischman MW (2001) Methamphetamine self-administration by humans. Psychopharmacology 157:75-81

Harvey DM, Yasar S, Heishman SJ, Panlilio LV, Henningfield JE, Goldberg SR (2004) Nicotine serves as an effective reinforcer of intravenous drug-taking behavior in human cigarette smokers. Psychopharmacology 175:134-142

Heil SH, Johnson MW, Higgins ST, Bickel WK (2006) Delay discounting in currently using and currently abstinent cocainedependent outpatients and non-drug-using matched controls. Addict Behav 31:1290-1294

Herd N, Borland R, Hyland A (2009) Predictors of smoking relapse by duration of abstinence: findings from the International Tobacco Control (ITC) Four Country Survey. Addiction 104:2088-2099

Herrnstein RJ (1961) Relative and absolute strength of response as a function of frequency of reinforcement. J Exp Anal Behav 4:267-272

Heyman GM (2003) Consumption dependent changes in reward value: a framework for understanding addiction. Pergamon, Pergamon

Hogarth L, Chase HW (2011) Parallel goal-directed and habitual control of human drug-seeking: implications for dependence vulnerability. J Exp Psychol: Anim Behav Processes (in press)

Hogarth L, Dickinson A, Duka T (2010) The associative basis of cue elicited drug taking in humans. Psychopharmacology 208: 337-351

Hogarth L, Dickinson A, Wright A, Kouvaraki M, Duka T (2007) The role of drug expectancy in the control of human drug seeking. J Exp Psychol Anim Behav Process 33:484-496

Holland PC (2004) Relations between Pavlovian-instrumental transfer and reinforcer devaluation. J Exp Psychol Anim Behav Process $30: 258-258$

Holmes NM, Marchand AR, Coutureau E (2010) Pavlovian to instrumental transfer: a neurobehavioural perspective. Neurosci Biobehav Rev 34:1277-1295

Hull CL (1943) Principles of behavior. Appleton-Century-Crofts, Appleton-Century-Crofts

Hursh SR, Silberberg A (2008) Economic demand and essential value. Psychol Rev 115:186-198

Hutcheson DM, Everitt BJ, Robbins TW, Dickinson A (2001) The role of withdrawal in heroin addiction: enhances reward or promotes avoidance? Nat Neurosci 4:943-947

Jacoby LL (1991) A process dissociation framework: separating automatic from intentional uses of memory. J Mem Lang 30:513-541

Jedynak JP, Uslaner JM, Esteban JA, Robinson TE (2007) Methamphetamine-induced structural plasticity in the dorsal striatum. Eur J Neurosci 25:847-853
Jose PE (2008) ModGraph-I: A programme to compute cell means for the graphical display of moderational analyses: the internet version. Victoria University of Wellington, Wellington

Killcross S, Coutureau E (2003) Coordination of actions and habits in the medial prefrontal cortex of rats. Cereb Cortex 13:400-408

Killen JD, Fortmann SP (1997) Craving is associated with smoking relapse: findings from three prospective studies. Exp Clin Psychopharmacol 5:137-142

Kosaki Y, Dickinson A (2010) Choice and contingency in the development of behavioral autonomy during instrumental conditioning. J Exp Psychol Anim Behav Process 36:334-342

Kühn S, Schubert F, Gallinat J (2010) Reduced thickness of medial orbitofrontal cortex in smokers. Biol Psychiatry 68:1061-1065

Lamb RJ, Preston KL, Schindler CW, Meisch RA, Davis F, Katz JL, Henningfield JE, Goldberg SR (1991) The reinforcing and subjective effects of morphine in post-addicts: a dose-response study. J Pharmacol Exp Ther 259:1165-1173

Le Foll B, Chefer SI, Kimes AS, Shumway D, Stein EA, Mukhin AG, Goldberg SR (2009) Baseline expression of alpha 4 beta $2 *$ nicotinic acetylcholine receptors predicts motivation to selfadminister nicotine. Biol Psychiatry 65:714-716

Lee B, London ED, Poldrack RA, Farahi J, Nacca A, Monterosso JR, Mumford JA, Bokarius AV, Dahlbom M, Mukherjee J, Bilder RM, Brody AL, Mandelkern MA (2009) Striatal dopamine D2/ D3 Rreceptor availability is reduced in methamphetamine dependence and is linked to impulsivity. J Neurosci 29:14734 14740

Leeman R, O'Malley S, White M, McKee S (2010) Nicotine and food deprivation decrease the ability to resist smoking. Psychopharmacology 212:25-32

Leventhal AM, Schmitz JM (2006) The role of drug use outcome expectancies in substance abuse risk: an interactional-transformational model. Addict Behav 31:2038-2062

Lieberman DA, Sunnucks WL, Kirk JD (1998) Reinforcement without awareness: I. Voice level. Q J Exp Psychol B 51:301-316

London ED, Ernst M, Grant S, Bonson K, Weinstein A (2000) Orbitofrontal cortex and human drug abuse: functional imaging. Cereb Cortex 10:334-342

Lovibond PF, Shanks DR (2002) The role of awareness in Pavlovian conditioning: empirical evidence and theoretical implications. J Exp Psychol Anim Behav Process 28:3-26

MacKillop J, Miranda R, Monti PM, Ray LA, Murphy JG, Rohsenow DJ, McGeary JE, Swift RM, Tidey JW, Gwaltney CJ (2010) Alcohol demand, delayed reward discounting, and craving in relation to drinking and alcohol use disorders. J Abnorm Psychol 119:106-114

Marusich JA, Bardo MT (2009) Differences in impulsivity on a delay-discounting task predict self-administration of a low unit dose of methylphenidate in rats. Behav Pharmacol 20: $447-454$

Matsuo K, Nicoletti M, Nemoto K, Hatch JP, Peluso MAM, Nery FG, Soares JC (2009) A voxel-based morphometry study of frontal gray matter correlates of impulsivity. Hum Brain Mapp 30:11881195

Maude-Griffin PM, Tiffany ST (1996) Production of smoking urges through imagery: the impact of affect and smoking abstinence. Exp Clin Psychopharmacol 4:198-208

McKee SA, Harrison ELR, O'Malley SS, Krishnan-Sarin S, Shi J, Tetrault JM, Picciotto MR, Petrakis IL, Estevez N, Balchunas E (2009) Varenicline reduces alcohol self-administration in heavydrinking smokers. Biol Psychiatry 66:185-190

Miles FJ, Everitt BJ, Dickinson A (2003) Oral cocaine seeking by rats: action or habit? Behav Neurosci 117:927-938

Moeller FG, Dougherty DM, Barratt ES, Schmitz JM, Swann AC, Grabowski J (2001) The impact of impulsivity on cocaine use and retention in treatment. J Subst Abuse Treat 21:193-198 
Moeller SJ, Maloney T, Parvaz MA, Dunning JP, Alia-Klein N, Woicik PA, Hajcak G, Telang F, Wang GJ, Volkow ND, Goldstein RZ (2009) Enhanced choice for viewing cocaine pictures in cocaine addiction. Biol Psychiatry 66:169-176

Mueller ET, Landes RD, Kowal BP, Yi R, Stitzer ML, Burnett CA, Bickel WK (2009) Delay of smoking gratification as a laboratory model of relapse: effects of incentives for not smoking, and relationship with measures of executive function. Behav Pharmacol 20:461-473

Nader MA, Morgan D, Gage HD, Nader SH, Calhoun TL, Buchheimer N, Ehrenkaufer R, Mach RH (2006) PET imaging of dopamine D2 receptors during chronic cocaine selfadministration in monkeys. Nat Neurosci 9:1050-1056

Nelson A, Killcross S (2006) Amphetamine exposure enhances habit formation. J Neurosci 26:3805-3812

Nemeth-Coslett R, Griffiths RR (1984a) Determinants of puff duration in cigarette smokers: I. Pharmacol Biochem Behav 20:965-971

Nemeth-Coslett R, Griffiths RR (1984b) Determinants of puff duration in cigarette smokers: II. Pharmacol Biochem Behav 21:903-912

Olmstead MC, Lafond MV, Everitt BJ, Dickinson A (2001) Cocaine seeking by rats is a goal-directed action. Behav Neurosci 115:394-402

Ostlund SB, Balleine BW (2008) The disunity of Pavlovian and instrumental values. Behav Brain Sci 31:456

Ostlund SB, Winterbauer NE, Balleine BW (2009) Evidence of action sequence chunking in goal-directed instrumental conditioning and its dependence on the dorsomedial prefrontal cortex. J Neurosci 29:8280-8287

Panlilio LV, Yasar S, Nemeth-Coslett R, Katz JL, Henningfield JE, Solinas M, Heishman SJ, Schindler CW, Goldberg SR (2005) Human cocaine-seeking behavior and its control by drug-associated stimuli in the laboratory. Neuropsychopharmacology 30:433-443

Patton JH, Stanford MS, Barratt ES (1995) Factor structure of the Barratt Impulsiveness Scale. J Clin Psychol 51:768-774

Pelloux Y, Everitt BJ, Dickinson A (2007) Compulsive drug seeking by rats under punishment: effects of drug taking history. Psychopharmacology 194:127-137

Perkins KA, Epstein LH, Grobe J, Fonte C (1994) Tobacco abstinence, smoking cues, and the reinforcing value of smoking. Pharmacol Biochem Behav 47:107-112

Perry JL, Carrol ME (2008) The role of impulsive behavior in drug abuse. Psychopharmacology 200:1-26

Perry JL, Larson EB, German JP, Madden GJ, Carroll ME (2005) Impulsivity (delay discounting) as a predictor of acquisition of IV cocaine self-administration in female rats. Psychopharmacology 178:193-201

Perry JL, Nelson SE, Carroll ME (2008) Impulsive choice as a predictor of acquisition of IV cocaine self-administration and reinstatement of cocaine-seeking behavior in male and female rats. Exp Clin Psychopharmacol 16:165-177

Poulos CX, Le AD, Parker JL (1995) Impulsivity predicts individual susceptibility to high levels of alcohol self-administration. Behav Pharmacol 6:810-814

Ray R, Jepson C, Patterson F, Strasser A, Rukstalis M, Perkins K, Lynch KG, O'Malley S, Berrettini WH, Lerman C (2006) Association of OPRM1 A118G variant with the relative reinforcing value of nicotine. Psychopharmacology 188:355-363

Rescorla RA (1994) Transfer of instrumental control mediated by a devalued outcome. Anim Learn Behav 22:27-33

Rescorla RA, Solomon RL (1967) Two-process learning theory: relationships between Pavlovian conditioning and instrumental learning. Psychol Rev 74:151-182

Robinson TE, Berridge KC (1993) The neural basis of drug craving: an incentive-sensitization theory of drug addiction. Brain Res Rev 18:247-291
Rose JE (2006) Nicotine and nonnicotine factors in cigarette addiction. Psychopharmacology 184:274-285

Scherrer JF, Grant JD, Duncan AE, Sartor CE, Haber JR, Jacob T, Bucholz KK (2009) Subjective effects to cannabis are associated with use, abuse and dependence after adjusting for genetic and environmental influences. Drug Alcohol Depend 105:76-82

Schiffer B, Muller BW, Scherbaum N, Forsting M, Wiltfang J, Leygraf N, Gizewski ER (2010) Impulsivity-related brain volume deficits in schizophrenia-addiction comorbidity. Brain 133:3093-3103

Schmitz JM, Mooney ME, Green CE, Lane SD, Steinberg JL, Swann AC, Moeller FG (2009) Baseline neurocognitive profiles differentiate abstainers and non-abstainers in a cocaine clinical trial. J Addict Dis 28:250-257

Seth AK, Dienes Z, Cleeremans A, Overgaard M, Pessoa L (2008) Measuring consciousness: relating behavioural and neurophysiological approaches. Trends Cogn Sci 12:314-321

Setlow B, Mendez IA, Mitchell MR, Simon NW (2009) Effects of chronic administration of drugs of abuse on impulsive choice (delay discounting) in animal models. Behav Pharmacol 20:380 389. doi:10.1097/FBP.0b013e3283305eb4

Shanks DR, St. John MF (1994) Characteristics of dissociable human learning systems. Behav Brain Sci 17:367-447

Sherva R, Wilhelmsen K, Pomerleau CS, Chasse SA, Rice JP, Snedecor SM, Bierut LJ, Neuman RJ, Pomerleau OF (2008) Association of a single nucleotide polymorphism in neuronal acetylcholine receptor subunit alpha 5 (CHRNA5) with smoking status and with 'pleasurable buzz' during early experimentation with smoking. Addiction 103:1544-1552

Silverman K, Kirby KC, Griffiths RR (1994) Modulation of drug reinforcement by behavioral requirements following drug ingestion. Psychopharmacology 114:243-247

Spiga R, Maxwell RS, Meisch RA, Grabowski J (2005) Human methadone self-administration and the generalized matching law. Psychol Rec 55:525-538

Staddon JER (1992) Rationality, melioration and law-of-effect models of choice. Psychol Sci (Wiley-Blackwell) 3:136-141

Stanford MS, Mathias CW, Dougherty DM, Lake SL, Anderson NE, Patton JH (2009) Fifty years of the Barratt Impulsiveness Scale: an update and review. Pers Individ Differ 47:385-395

Tarter RE, Kirisci L, Habeych M, Reynolds M, Vanyukov M (2004) Neurobehavior disinhibition in childhood predisposes boys to substance use disorder by young adulthood: direct and mediated etiologic pathways. Drug Alcohol Depend 73:121-132

Thorndike EL (1911) Animal intelligence: experimental studies. Macmillan, Macmillan

Tiffany ST (1990) A cognitive model of drug urges and drug-use behaviour: role of automatic and nonautomatic processes. Psychol Rev 97:147-168

Tiffany ST, Cox LS, Elash CA (2000) Effects of transdermal nicotine patches on abstinence-induced and cue-elicited craving in cigarette smokers. J Consult Clin Psychol 68:233-240

Tiffany ST, Warthen MW, Goedeker KC (2007) The functional significance of craving in nicotine dependence. In: Bevins RA, Caggiuls AR (eds) 55th Annual Nebraska symposium on motivation-motivational impact of nicotine and its role in tobacco use, Lincoln, NE, pp 171-197

Tricomi E, Balleine BW, O'Doherty JP (2009) A specific role for posterior dorsolateral striatum in human habit learning. Eur $\mathrm{J}$ Neurosci 29:2225-2232

Vanderschuren LJMJ, Everitt BJ (2004) Drug seeking becomes compulsive after prolonged cocaine self-administration. Science 305:1017-1019

Verdejo-García A, Lawrence AJ, Clark L (2008) Impulsivity as a vulnerability marker for substance-use disorders: review of findings from high-risk research, problem gamblers and genetic association studies. Neurosci Biobehav Rev 32:777-810 
Volkow ND, Wang G-J, Fowler JS, Logan J, Gatley SJ, Gifford A, Hitzemann R, Ding Y-S, Pappas N (1999) Prediction of reinforcing responses to psychostimulants in humans by brain dopamine D2 receptor levels. Am J Psychiatry 156:1440-1443

Volkow ND, Wang GJ, Fowler JS, Thanos P, Logan J, Gatley SJ, Gifford A, Ding YS, Wong C, Pappas N (2002) Brain DA D2 receptors predict reinforcing effects of stimulants in humans: replication study. Synapse 46:79-82

Volkow ND, Fowler JS, Wang GJ, Baler R, Telang F (2009) Imaging dopamine's role in drug abuse and addiction. Neuropharmacology $56: 3-8$

Walsh SL, Donny EC, Nuzzo PA, Umbricht A, Bigelow GE (2010) Cocaine abuse versus cocaine dependence: cocaine selfadministration and pharmacodynamic response in the human laboratory. Drug Alcohol Depend 106:28-37
Waters AJ, Shiffman S, Sayette MA, Paty JA, Gwaltney CJ, Balabanis $\mathrm{MH}$ (2004) Cue-provoked craving and nicotine replacement therapy in smoking cessation. J Consult Clin Psychol 72:11361143

Willner P, Hardman S, Eaton G (1995) Subjective and behavioral evaluation of cigarette cravings. Psychopharmacology 118:171-177

Winstanley CA (2007) The orbitofrontal cortex, impulsivity, and addiction-Probing orbitofrontal dysfunction at the neural, neurochemical, and molecular level Linking Affect to Action: Critical Contributions of the Orbitofrontal Cortex (Annals of the New York Academy of Sciences). Blackwell Publishing, Oxford, pp 639-655

Zapata A, Minney VL, Shippenberg TS (2010) Shift from goaldirected to habitual cocaine seeking after prolonged experience in rats. J Neurosci 30:15457-15463 